\title{
Using functional imaging to understand therapeutic effects in post- stroke aphasia
}

\section{Jennifer T. Crinion ${ }^{1} \&$ Alexander P. Leff ${ }^{1,2}$}

${ }^{1}$ Neurotherapuetics Group, Institute of Cognitive Neuroscience, \& ${ }^{2}$ Department of Brain Repair and Rehabilitation, Institute of Neurology, University College London, Queen Square, London, UK.

Correspondence to Dr Jennifer Crinion, Wellcome Trust Senior Clinical Fellow, Institute of Cognitive Neuroscience, 17 Queen Square, London, WC1N 3AR.

Tel: +44 (0) 2076791129

e-mail: j.crinion@ucl.ac.uk

Word count (excluding abstract and references): 2461 


\section{Abstract (202)}

\section{Purpose of review}

The evidence base for the treatment of post-stroke aphasia continues to grow, so too does interest in the neural mechanisms that underlie these therapy-driven improvements. While the majority of patients respond to therapy, not all of those that do improve do so in a predictable way. Here we review 17 of the most recent articles that have attempted to deal with this important question, dividing them into those that target speech perception and production.

\section{Recent findings}

There are many methodological differences between the studies but some neuroimaging patterns have emerged: 1) whether the in-scanner language task is speech perception or production, left hemisphere fronto-temporal cortex is often activated/correlated with language improvement; 2) right inferior frontal gyrus is frequently identified although what this represents is still hotly contested. We are concerned that many studies are not well controlled making it difficult to ascribe neuroimaging changes directly to the therapeutic intervention.

\section{Summary}

Encouragingly there are many more functional imaging studies in this challenging area of research. Behaviour, either alone or paired with structural imaging data, only goes part way to explaining aphasic patients' responses to therapy. An important emerging theme is exploring the role non-language cognitive processes play in aphasia recovery.

\section{Keywords}

Aphasia, therapy, stroke, functional neuroimaging, 


\section{Introduction}

We searched Google Scholar and PubMed for peer-reviewed studies published in the last 15 months that both provided speech therapy to patients with post-stroke aphasia, and used some form of functional imaging to try and capture behaviour change. We found $n=17$ studies and divided them into those that used a speech perception task for the functional imaging experiment $(n=7)$, and those that used speech production $(n=10)$. In order to discuss the papers rather than simply describe them, we have summarized the main design, patient cohorts, method of treatment and imaging outcomes in Table 1.

Controlling for the effects of a complex intervention such as speech therapy is never straightforward [1]. When the effects of 'spontaneous recovery' are likely to be large e.g., in acute phase studies where the time-post stroke/therapy time ratio is small, it is perhaps best to have a control group. When this ratio is much larger (usually in chronic phase studies) a control group can still be used; or another option is to have a within-subject control (either a control block with no therapy, or multiple baseline measurements). It is not uncommon for chronic phase studies to have neither. Authors usually argue that spontaneous recovery effects will be so low as to be safe to ignore, but this still leaves test/retest, variability and regression to the mean effects [2]. These are important to control for, especially when effect sizes are small. In Table 1 for each study we record the type of control accordingly: group/block/baseline/none. We also report absolute (percentage change) effect sizes where possible.

\section{Perception of language}

In a single-case study design, Aerts et al. followed the effects of 90 hours of speech therapy (that included elements of auditory training) on a patient with acute, global aphasia using EEG [3]. As the therapy started on day 10 post-stroke and finished on day 105 it was no surprise that many of his language measures improved. The ERP that showed the greatest change over time was the N400 component in response to hearing pseudowords, although responses to real word stimuli did not mirror this. This causes an interpretive problem as the main aim of speech therapy is to improve responses to long-standing (already learnt) language representations, rather, than novel ones. In the final phase ( month 10$)$ the same N400 response significantly reduced while behavioural scores remained stable, casting considerable doubt on how well this measure 
actually tracks linguistic capabilities. The main criticism of this study is that there was no good control for the rapid improvements that are seen in many patients in the acute post-stroke period, regardless of therapy provision.

To avoid this problem Mattioli et al. designed a small group study with a control group who received no therapy [4]. The therapy started very early, just two days post-stroke, so it is perhaps not surprising that overall recovery attributable to therapy $(5 \%)$ was smaller than in the control group $(10 \%)$, although still significantly greater for naming and writing skills. The imaging paradigm was the same as used by Saur [5], targeting speech comprehension. Therapy specific effects were seen in the left inferior frontal gyrus (IFG) with a nice, positive correlation with behaviour $(n=6)$. This study demonstrates that speech therapy can have positive behavioural effects in the acute setting and is largely in agreement with Saur's suggestion that the left IFG can be recruited to support behavioural improvements in the early post-stroke phase.

Bettina Mohr's group report the results of intensive language action therapy (ILAT) on a group of chronic aphasic patients across two papers [6,7]. The patients improved over the therapy blocks with a significant 7\% improvement in the Boston Naming Test and Token Test (TT) scores, but unfortunately the study was neither baseline nor block controlled. The mismatch negativity findings were very clear with a left-hemisphere ("fronto-temporal regions") increase in response to real words compared with pseudowords, mirroring Mattioli et al.'s results. A subset $(n=6)$ of these patients also took part in an fMRI paradigm that found therapy-related changes in the right hemisphere (BOLD responses to semantically ambiguous sentences). This may seem counter-intuitive, but given that the two imaging modalities differed, as did the tasks used, it may well be that they are both 'correct', and are picking up on different aspects of improved linguistic ability.

Brownsett et al.'s is a rather unusual study. While therapy was included, the main imaging effects they report were in non-language areas where fMRI-behavioural correlations were demonstrated irrespective of any therapy effects [8]. 16 patients in the chronic phase listened to sentences at three time points (twice before therapy). They found activity in both task-specific regions (e.g., temporal cortex) and in domain-general cognitive control systems (dorsal anterior cingulate cortex and superior frontal gyrus). Activity in these latter regions correlated positively with performance on an out-of-scanner language task: spoken picture description. The authors argue cogently that executive cognitive function must have a role to play in aphasia recovery and, intriguingly, perhaps domain-general networks (which are spared by MCA stroke) would make a good target for focal therapies (e.g., non-invasive brain stimulation). 
Thus far we have discussed studies looking at task-related changes in the scanner. Others have chosen to focus on state-related changes or resting-state data. Given recent work highlights the importance of sleep on learning [9], one group used a sleep related EEG spectral measure (Slow wave Activity: SWA) to try and capture the effect of a single dose of high intensity therapy [10]. 13 patients were tested before and one day after a single session of IMITATE therapy, which focuses on speech repetition. There was no baseline control, which is a shame as test-retest effects are difficult to ignore over a $24 \mathrm{hr}$ period. The authors chose to Bonferroni correct their 16 language outcome measures which is both unusual and theoretically flawed, because the measures would have correlated with each other to some degree and are thus not independent. They found no significant behavioural effects. They did however identify a significant correlation between the Western Aphasia Battery (WAB) repetition score and the change in SWA in electrodes overlying left premotor cortex. As SWA is thought to reflect changes in synaptic strength in local networks, this may well be a promising approach. Moving onto studies of resting-state $\mathrm{AMRI}$, Zhu et al. studied 14 aphasic patients with Chinese as their first language one month post-stroke and again a month later [11]. Between these two time points patients received a low-dose of speech therapy; unfortunately there was no control. The patients improved a great deal, as one might expect, but it is difficult to attribute this to the therapy itself. Their resting-state analysis revealed an increase in connectivity in the left frontoparietal network that correlated with recovery of speech comprehension. Resting-state fMRI has its critics, but its big advantage is that it has translational potential (to clinical scanners and teams) compared with more time-consuming and research-group dependent task-related paradigms.

\section{Production of language}

Three very different approaches for improving chronic aphasics' speech and brain function have been used in AMRI studies over the last year: 1) anomia training, 2) melodic training and 3) upper limb motor training.

\section{Anomia Training}

The majority of studies investigated neural activity changes associated with anomia treatment outcomes. In the largest group study Abel and colleagues found that 9/14 aphasic patients $(>4$ months post-stroke) significantly responded to treatment with improved naming performance in the fMRI scanner [12]. Therapy was associated with activation decreases in the naming network bilaterally; most commonly left IFG. They attributed this finding to improved naming efficiency.

Activation increases in the prefrontal cortices were attributed to higher demands on cognitive 
control processes. In a second paper they performed additional analyses on specific therapy effects for the same patient group [13]. While the authors focus their discussions on the relative differences between semantic versus phonological anomia treatment approaches the clearest results emerge from the overall treatment effects. Here left IFG activation (along with lesion damage to this region) was a positive predictor of recovery.

Van Hees and colleagues [14] adopted a very similar approach in their study of eight patients (>17 months post stroke). $7 / 8$ patients improved naming in response to phonological treatment, only $4 / 8$ to semantic treatment. Consistent with Abel's studies, greater phonological therapy outcomes were associated with perilesional activation of left hemisphere language networks. However, in this group of patients it was an increase in left supramarginal gyrus (SMG) activity that correlated with treatment success. A second paper reported additional functional connectivity analyses of resting-state data from the same patient group compared to healthy controls [15]. Here they found post treatment both normalization and up-regulation of connectivity, predominantly in left hemisphere language networks (SMG and middle temporal gyrus: MTG) and between left and right IFG. Together with the two cases of subcortical aphasia presented by Della Rose and colleagues [16] these studies suggest that preservation of effective connectivity both within the left hemisphere (fronto-temporal) language network and interhemispheric IFG appear to play a major role in anomia recovery.

However when left hemisphere networks are extensively damage anomia recovery is still possible. Toumiranta et al. report a patient with extensive left dorsal temporo-frontal damage [17]. Unusually she only benefitted from orthographic as opposed to (standard) auditory cues when naming. Written cues enabled her to learn and maintain over 6 months novel words to a comparable level as healthy controls demonstrating her intact learning potential. Given a modified anomia treatment package using written cues she improved not only her naming but also her connected speech abilities. She had an aneurysm clip in the vicinity of the left IFG so MRI data here was distorted. However, when reading she significantly activated the right temporal and parietal regions suggesting connectivity within a right hemisphere network was proving an effective route in her recovery.

\section{Melodic training}

The effects of melodic training on brain activation and speech function were investigated in two studies. Al-Janabi et al. [18] combined Melodic Intonation Therapy (MIT) with excitatory transcranial magnetic stimulation (TMS) delivered to right Broca's area in two aphasic patients. One improved on fluency and repetition tasks. During an automatic-speech fMRI task, compared 
to pretreatment $\mathrm{AMRI}$, this subject had increased activity in left and decreased activity in right Broca's regions. The other patient showed no behavioural improvement but increased activation bilaterally in IFG making it hard to interpret the fMRI data. In Jungblut et al.'s study [19] they used the SIPARI method (singing, intonation, prosody, breathing (German: Atmung), rhythm and improvisation) [20] to treat three patients with aphasia and speech apraxia. After 6 months' treatment all patients were significantly better at producing regular rhythmic vowel changes e.g., /a/i/. This was associated with increased left perilesional activation, commonly the left superior temporal gyrus. 2/3 patients also improved on the token-test and naming sections of the Aachen Aphasia Test. The authors suggest that the observed change in language function may not just be due to vocal motor training but more domain general cognitive functions such as planning and sequencing that are key components of the melodic training.

\section{Upper limb motor training}

The two upper-limb training papers adopt a very different approach to aphasia treatment. Harnish et al. [21] noted that $3 / 5$ patients who had intensive upper limb rehabilitation not only significantly improved their treated motor function but also their untreated language function, as measured by the WAB. fMRI activation during a finger-tapping task shifted rightward (frontally) post treatment in these same patients. To explain why language and motor improvements might covary, the authors quote work by Gentilucci and Dalla Volta [22] who argue that speech and arm movements are controlled by the same neural system. Benjamin et al.'s [23] study of 14 chronic aphasics follows up on this approach. Half of their patients completed a block of classical anomia training (CT) the rest anomia training in conjunction with moving their left hand (IT). The hypothesis being if hand movements and speech production are linked through mirror neurons in the pars opercularis, then this motor adjuvant would facilitate activation in right frontal cortices and aid speech recovery. Behaviourally both IT and CT improved naming to the same degree. There was a significant rightward frontal shift following IT but it did not correlate with speech treatment gains. An unexpected activation change in right posterior perisylvian regions correlated with category naming for the IT group alone. Thus the mechanism of this upper limb adjuvant treatment approach or the evidence of its behavioural benefit is far from clear.

\section{Conclusions}

It is promising to see so many international groups working in this rather difficult field of research. The studies presented here are varied in their patient populations, therapy regimens and imaging modalities, so it is not possible to generate any simple, functional imaging recovery models that will fit them all. Nonetheless, some neuroimaging patterns do emerge: 1) whether 
the in-scanner language task is speech perception or production, left hemisphere fronto-temporal cortex is often activated/correlated with language improvement; 2) right IFG is also frequently identified (particularly in output studies) although the jury is still out on whether this represents true therapy-induced, language (re)lateralization or engagement of the domain-general, cognitive control system. One explanation for the lack of common findings across studies may be that we have become overly fixated on regional changes e.g., "Is the left or right hemisphere supporting recovery?", "Does the BOLD signal increase or decrease in response to therapy?" Perhaps with neuroimaging we are only glimpsing different parts of a generally conserved but distributed neural network(s) that supports recovery? If so, perhaps we should turn to more connectivitybased analyses. The therapeutic effects, driving recovery may simply not be in distinct regions themselves, but in their interregional connectivity.

An important emerging question involves the role of non-language cognitive process involved in aphasia recovery, and how these may manifest in functional imaging data. We (and many others) are interested in what we loosely term 'the capacity to learn' which interacts with behavioural therapy and can be formalized as: for a given dose of appropriate therapy, how much will this patient improve? This capacity varies between patients, even when they have similar language impairments and perhaps even over time within patients. It is clearly multifaceted and draws on many cognitive processes (e.g.: attention, engagement, self-monitoring, fluid intelligence) as well as cognitive control process discussed by many of the papers in this review. Given that the neural substrates for language and non-language processes may overlap, researchers need to think carefully about how they control for task difficulty between groups and/or across time, otherwise it will be difficult to distinguish between linguistic and non-linguistic drivers of neural change. This begs an even more important question: 'Should aphasia therapies (and the functional imaging paradigms designed to capture change) be targeted at the language impairments themselves or rather patients' capacity to learn?'

\section{Bullet points}

- A change in the functional activity of left hemisphere fronto-temporal cortex is correlated with language improvement in aphasic patients.

- Right inferior frontal gyrus activity is also frequently identified although what this represents is still hotly contested.

- Many studies are not well controlled making it difficult to ascribe neuroimaging changes directly to the therapeutic intervention.

- An area of current interest is the role that non-language cognitive processes play in aphasia recovery. 


\section{References}

1. Leff AP, Howard D: Stroke: Has speech and language therapy been shown not to work? Nat Rev Neurol 2012, 8:600-601.

2. Barnett AG, van der Pols JC, Dobson AJ: Regression to the mean: what it is and how to deal with it. International Journal of Epidemiology 2005, 34:215-220.

3. Aerts A, Batens K, Santens P, Van Mierlo P, Huysman E, Hartsuiker R, Hemelsoet D, Duyck W, Raedt R, Van Roost D, et al.: Aphasia therapy early after stroke: behavioural and neurophysiological changes in the acute and post-acute phases. Aphasiology 2015:127.

4. Mattioli F, Ambrosi C, Mascaro L, Scarpazza C, Pasquali P, Frugoni M, Magoni M, Biagi L, Gasparotti R: Early Aphasia Rehabilitation Is Associated With Functional Reactivation of the Left Inferior Frontal Gyrus A Pilot Study. Stroke 2014, 45:545552.

5. Saur D, Lange R, Baumgaertner A, Schraknepper V, Willmes K, Rijntjes M, Weiller C: Dynamics of language reorganization after stroke. Brain 2006, 129:1371-1384.

6. MacGregor LJ, Difrancesco S, Pulvermuller F, Shtyrov Y, Mohr B: Ultra-Rapid Access to Words in Chronic Aphasia: The Effects of Intensive Language Action Therapy (ILAT). Brain Topography 2015, 28:279-291.

7. Mohr B, Difrancesco S, Harrington K, Evans S, Pulvermuller F: Changes of righthemispheric activation after constraint-induced, intensive language action therapy in chronic aphasia: fMRI evidence from auditory semantic processing. Frontiers in Human Neuroscience 2014, 8.

8. Brownsett SLE, Warren JE, Geranmayeh F, Woodhead Z, Leech R, Wise RJS: Cognitive control and its impact on recovery from aphasic stroke. Brain 2014, 137:242-254.

9. Huber R, Ghilardi MF, Massimini M, Tononi G: Local sleep and learning. Nature 2004, 430:78-81.

10. Sarasso S, Maatta S, Ferrarelli F, Poryazova R, Tononi G, Small SL: Plastic Changes Following Imitation-Based Speech and Language Therapy for Aphasia: A HighDensity Sleep EEG Study. Neurorehabilitation and Neural Repair 2014, 28:129-138.

11. Zhu D, Chang JL, Freeman S, Tan ZJ, Xiao J, Gao Y, Kong J: Changes of functional connectivity in the left frontoparietal network following aphasic stroke. Frontiers in Behavioral Neuroscience 2014, 8.

12. Abel S, Weiller C, Huber W, Willmes K, Specht K: Therapy-induced brain reorganization patterns in aphasia. Brain 2015, 138:1097-1112. 
13. Abel S, Weiller $\mathrm{C}$, Huber $\mathrm{W}$, Willmes $\mathrm{K}$ : Neural underpinnings for model-oriented therapy of aphasic word production. Neuropsychologia 2014, 57:154-165.

14. van Hees S, McMahon K, Angwin A, de Zubicaray G, Copland DA: Neural activity associated with semantic versus phonological anomia treatments in aphasia. Brain Lang 2014, 129:47-57.

15. van Hees S, McMahon K, Angwin A, de Zubicaray G, Read S, Copland DA: A Functional MRI Study of the Relationship Between Naming Treatment Outcomes and Resting State Functional Connectivity in Post-Stroke Aphasia. Human Brain Mapping 2014, 35:3919-3931.

16. Della Rosa PA, Canini M, Borsa VM, Marien P, Cappa SF, Abutalebi J: Functional recovery in subcortical crossed and standard aphasia. Journal of Neurolinguistics 2014, 27:103-118.

17. Tuomiranta LM, Camara E, Froudist Walsh S, Ripolles P, Saunavaara JP, Parkkola R, Martin N, Rodriguez-Fornells A, Laine M: Hidden word learning capacity through orthography in aphasia. Cortex 2014, 50:174-191.

18. Al-Janabi S, Nickels LA, Sowman PF, Burianova H, Merrett DL, Thompson WF: Augmenting melodic intonation therapy with non-invasive brain stimulation to treat impaired left-hemisphere function: two case studies. Front Psychol 2014, 5:37.

19. Jungblut M, Huber W, Mais C, Schnitker R: Paving the Way for Speech: Voice-TrainingInduced Plasticity in Chronic Aphasia and Apraxia of Speech-Three Single Cases. Neural Plasticity 2014.

20. Bradt J, Magee WL, Dileo C, Wheeler BL, McGilloway E: Music therapy for acquired brain injury. Cochrane Database of Systematic Reviews 2010.

21. Harnish S, Meinzer M, Trinastic J, Fitzgerald D, Page S: Language changes coincide with motor and fMRI changes following upper extremity motor therapy for hemiparesis: a brief report. Brain Imaging and Behavior 2014, 8:370-377.

22. Gentilucci M, Volta RD: Spoken language and arm gestures are controlled by the same motor control system. Quarterly Journal of Experimental Psychology 2008, 61:944-957.

23. Benjamin ML, Towler S, Garcia A, Park H, Sudhyadhom A, Phd SH, McGregor KM, Zlatar Z, Reilly JJ, Rosenbek JC, et al.: A Behavioral Manipulation Engages Right Frontal Cortex During Aphasia Therapy. Neurorehabilitation and Neural Repair 2014, 28:545-553. 


\section{Summaries of selected refs:}

Mattioli [4]

Well-designed study (both in terms of therapy and functional neuroimaging outcomes), although with a rather small number of patients. They show that it is possible to capture therapy effects in the acute phase and found a nice correlation in spared left IFG between therapy effects and inscanner task.

MacGregor [6] •

Strong evidence for word-level therapy effects in left IFG using a well-balanced MMN study design. A bit disappointing that no within-subject control was built into the design.

Brownsett [8]

Intriguing study that highlights the role that non-linguistic brain networks play in the role of recovery from aphasic stroke. Finings focused brain behaviour correlations in domain-general, cognitive control systems.

Sarasso [10] •

A poorly controlled study but with a tantalizing finding that therapy effects can be focally captured using sleep-related brainwave changes (SWA) thought to represent synaptic remodelling.

\section{Abel [12] •}

A paper combining $\mathrm{AMRI}$ with joint ICA for the first time to investigate the relationship between brain reorganisation patterns due to anomia therapy and lesion sites in 14 chronic aphasics. Therapy was associated with activation decreases within the naming network (improved efficiency), particular focus on the left IFG.

Tuomiranta[17]•

Intriguing single case study. FMRI word learning task was poor designed but very nice series of behavioural experiments displaying clearly that given the right therapeutic approach (orthographic cues) the patient had intact learning potential (novel words) that in turn facilitated her anomia treatment. 


\section{Acknowledgements}

None.

\section{Financial support and sponsorship}

This work was supported by the National Institute for Health Research University College London Hospitals Biomedical Research Centre.

\section{Conflicts of interest}

Neither author has any conflicts of interest to report. 
Technical summary of the imaging studies discussed in this paper

\begin{tabular}{|c|c|c|c|c|c|}
\hline Author [ref] & $\begin{array}{l}\text { Aphasia type, } \mathbf{n} \text {, lesion } \\
\text { location and control } \\
\text { group } \\
\text { (acute/chronic; } \mathbf{n} \text {; } \\
\text { lesion location; control } \\
\text { group/block/bas eline) }\end{array}$ & $\begin{array}{l}\text { The rapy type and } \\
\text { dose } \\
\text { (total session; total } \\
\text { hours; target: } \\
\text { output/input; name } \\
\text { of the rapy) } \\
\end{array}$ & $\begin{array}{c}\text { Behavioural e ffect size } \\
\text { (Absolute\% improvement ) }\end{array}$ & Imaging (modality and task) & Main imaging findings \\
\hline \multicolumn{6}{|c|}{ 1.Spe ech perception/resting-state connectivity } \\
\hline Aerts [3] & $\begin{array}{l}\text { Acute; } 1 \text {; non-fluent; Lt } \\
\text { F-P-T(minor)-I-BG; } \\
\text { control period }\end{array}$ & $\begin{array}{l}45 \text { sessions; } 90 \text { hours; } \\
\text { mixed but included } \\
\text { phonological to } \\
\text { semantic matching of } \\
\text { real words }\end{array}$ & $\begin{array}{l}\text { 1) Lexical decision (pseudo- } \\
\text { words) } 10 \% \\
\text { 2) Repetition (pseudo-words) } \\
20 \%\end{array}$ & $\begin{array}{l}\text { EEG: MMN, P300 and N400 } \\
\text { in two paradigms: 1) auditory } \\
\text { mismatch with consonants } \\
\text { varying in phonemes; 2) } \\
\text { auditory mismatch with real } \\
\text { word vs. pseudo-words }\end{array}$ & $\begin{array}{l}\text { Increase (normalization) in N400 } \\
\text { to pseudowords after therapy, in } \\
\text { keeping with behavioural } \\
\text { improvement; but after control } \\
\text { period (no therapy), the same } \\
\text { N400 response decreased while } \\
\text { behaviour remained stable }\end{array}$ \\
\hline Mattioli [4] & $\begin{array}{l}\text { Acute; } 12 ; 8 \text { Broca, } 3 \\
\text { anomic, } 1 \text { Wernicke; } \\
\text { mixed lesion site (all left } \\
\text { MCA); control group } \\
\text { (6:6 randomized) }\end{array}$ & $\begin{array}{l}10 \text { sessions; } 10 \text { hours; } \\
\text { mixed both input and } \\
\text { output (confrontation } \\
\text { naming) }\end{array}$ & $\begin{array}{l}\text { Relative to control group } \\
\text { 1) Naming } 4 \% \\
\text { 2) Writing } 6 \%\end{array}$ & $\begin{array}{l}\text { fMRI: auditory; intelligible } \\
\text { sentences vs. unintelligible } \\
\text { (time-reversed) and } \\
\text { background noise }\end{array}$ & $\begin{array}{l}\text { Therapy group showed increased } \\
\text { activation of Left IFG compared } \\
\text { with controls, after therapy. } \\
\text { Activity here correlated positively } \\
\text { with increased behavioural scores. }\end{array}$ \\
\hline Mohr [7] & $\begin{array}{l}\text { Chronic; } 8 \text { (subset of the } \\
12 \text { in MacGregor); non } \\
\text { fluent; mixed site (all } \\
\text { left MCA); no control }\end{array}$ & $\begin{array}{l}10 \text { sessions; } 35 \text { hours; } \\
\text { both input and output; } \\
\text { ILAT }\end{array}$ & $\begin{array}{l}\text { Relative to single baseline } \\
\text { 1) BNT 7\% } \\
\text { 2) TT 7\% }\end{array}$ & $\begin{array}{l}\text { fMRI: auditory sentence task } \\
\text { (semantic ambiguity: } \\
\text { unambiguous > ambiguous) }\end{array}$ & $\begin{array}{l}\text { Combined right frontal and } \\
\text { temporal ROIs showed a reduced } \\
\text { difference between unambiguous } \\
\text { and ambiguous sentences post- } \\
\text { therapy. }\end{array}$ \\
\hline $\begin{array}{l}\text { MacGregor } \\
\text { [6] }\end{array}$ & $\begin{array}{l}\text { Chronic; 12; non fluent; } \\
\text { mixed site (all left } \\
\text { MCA); no control }\end{array}$ & $\begin{array}{l}10 \text { sessions; } 35 \text { hours; } \\
\text { both input and output; } \\
\text { ILAT }\end{array}$ & $\begin{array}{l}\text { Relative to single baseline } \\
\text { 1) BNT 7\% } \\
\text { 2) TT } 10 \%\end{array}$ & $\begin{array}{l}\text { MEG: MMN design with real } \\
\text { word and pseudowords } \\
\text { contrasted }\end{array}$ & $\begin{array}{l}\text { Responses to realword deviants } \\
\text { (MMN) greater in left fronto- } \\
\text { temporal cortex compared with } \\
\text { the right, after therapy. }\end{array}$ \\
\hline Sarasso [10] & $\begin{array}{l}\text { Chronic; } 13 ; 5 \text { Broca, } 6 \\
\text { anomic, } 1 \text { conduction, } 1 \\
\text { Wernicke; mixed site } \\
\text { (all left MCA, mainly F- } \\
\text { P and I); no control }\end{array}$ & $\begin{array}{l}\text { 1 session of } 3.5 \text { hours; } \\
\text { IMITATE (watch and } \\
\text { listen to videos of } \\
\text { speech then repeat } \\
\text { aloud) }\end{array}$ & $\begin{array}{l}\text { Relative to single baseline } \\
\text { 1) WAB repetition score } 4 \%\end{array}$ & $\begin{array}{l}\text { Sleep EEG: slow-wave activity } \\
\text { (SWA) }\end{array}$ & $\begin{array}{l}\text { Changes in SWA over the left- } \\
\text { precentral areas predicted changes } \\
\text { in WAB repetition scores }\end{array}$ \\
\hline
\end{tabular}




\begin{tabular}{|c|c|c|c|c|c|}
\hline Zhu [11] & $\begin{array}{l}\text { Sub-acute ( } 1 \text { and } 2 \\
\text { months after stroke), 14; } \\
8 \text { Broca, } 1 \text { anomic, } 1 \\
\text { conduction, } 5 \text { global; } \\
\text { mixed site (all left } \\
\text { MCA, mainly F and } \\
\text { striato-capsular); no } \\
\text { control }\end{array}$ & $\begin{array}{l}\sim 12 \text { sessions between } \\
\text { the two scans; } \sim 6 \\
\text { hours; mixed } \\
\text { "conventional" therapy }\end{array}$ & $\begin{array}{l}\text { Relative to single baseline } \\
\text { 1) comprehension } 21 \% \\
\text { 2) production } 23 \%\end{array}$ & $\begin{array}{l}\text { fMRI: resting state ICA nb: } \\
\text { only } 8 \text { completed both } \\
\text { scanning sessions }\end{array}$ & $\begin{array}{l}\text { Patients who exhibited the highest } \\
\text { level of comprehension } \\
\text { improvement showed the highest } \\
\text { increase in mean left } \\
\text { frontoparietal network } \\
\text { connectivity }\end{array}$ \\
\hline $\begin{array}{l}\text { Brownsett } \\
{[8]}\end{array}$ & $\begin{array}{l}\text { Chronic; 16; all with } \\
\text { auditory comprehension } \\
\text { and repetition deficits; } \\
\text { mixed site (all left } \\
\text { MCA, mainly F-T); no } \\
\text { control }\end{array}$ & $\begin{array}{l}3 \text { sessions per day; } 20 \\
\text { hours; Home based } \\
\text { computerized auditory } \\
\text { discrimination } \\
\text { therapy* }\end{array}$ & $\begin{array}{l}\text { Relative to single baseline* } \\
\text { 1) auditory discrimination } \\
6 \%\end{array}$ & $\begin{array}{l}\text { fMRI: listening to sentences } \\
\text { (and then repeating them back) }\end{array}$ & $\begin{array}{l}\text { Listening to sentences activated } \\
\text { regions involved in both } \\
\text { language-specific and domain } \\
\text { general processes. Activity in } \\
\text { midline frontal cortex (domain } \\
\text { general system) correlated } \\
\text { significantly with the patients' } \\
\text { communicative abilities both } \\
\text { before and after therapy. }\end{array}$ \\
\hline \multicolumn{6}{|c|}{ 11. Spe ech production } \\
\hline Harnish [21] & $\begin{array}{l}\text { Chronic ( }>1 \text { year) 5; } \\
2 \text { Left Temporal } \\
2 \text { Left fronto-temporal } \\
\text { Left subcortical } \\
\text { Mixed WAB AQ scores } \\
\text { (range 78-93) } \\
\text { no control } \\
\text { pre-post case series } \\
\text { design. }\end{array}$ & $\begin{array}{l}\text { 1) intensive motor arm } \\
\text { training [ } 65 \text { hours over } \\
6 \text { weeks]; } \\
\text { 2) adjuvant: epidural } \\
\text { cortical stimulation } \\
\text { (for 3) }\end{array}$ & $\begin{array}{l}3 / 5 \text { improved language and } \\
\text { motor function. } \\
\text { WAB } 5.3 \% \text {; FM } 13 \% \text {. }\end{array}$ & $\begin{array}{l}\text { fMRI: pre and directly post } \\
\text { treatment. } \\
\text { Task: finger tapping motor } \\
\text { task. }\end{array}$ & $\begin{array}{l}\text { In the } 3 / 5 \text { who responded to the } \\
\text { treatment: there was a } \\
\text { right laterality shift and more } \\
\text { focal BOLD signal in frontal } \\
\text { motor regions. }\end{array}$ \\
\hline $\begin{array}{l}\text { Benjamin } \\
{[23]}\end{array}$ & $\begin{array}{l}\text { Chronic (>6 months); } \\
\text { 14-9 had concomitant } \\
\text { speech apraxia; left } \\
\text { frontal lesions involving } \\
\text { at least the precentral } \\
\text { gyrus or underlying } \\
\text { white matter; between } \\
\text { group comparison. }\end{array}$ & $\begin{array}{l}\text { Anomia treatment } \\
\text { without (Control } \\
\text { treatment-CT) or with } \\
\text { adjuvant of left-hand } \\
\text { movements (intention } \\
\text { treatment-IT): } 30 \\
\text { sessions over } 3 \text { weeks. }\end{array}$ & $\begin{array}{l}\text { Both groups improved. } \\
\text { Overall picture naming: } \\
\text { IT } 20 \% \text { : CT } 22 \% \text {; } \\
\text { category naming tasks : } \\
\text { IT } 15 \% \text {; CT } 12 \% \text {. }\end{array}$ & $\begin{array}{l}\text { fMRI: pre, directly post and } 3 \\
\text { months post treatment. } \\
\text { Task: } 60 \text { trials where patients } \\
\text { heard and read a category } \\
\text { word and generated a single } \\
\text { word member. }\end{array}$ & $\begin{array}{l}\text { Post treatment and at } 3 \text { month } \\
\text { follow-up IT patients had } \\
\text { increased rightward frontal } \\
\text { laterality. The CT group did not. } \\
\text { This LI (laterality index) change } \\
\text { did not correlate with language } \\
\text { function. }\end{array}$ \\
\hline
\end{tabular}




\begin{tabular}{|c|c|c|c|c|c|}
\hline $\begin{array}{l}\text { Van Hees } \\
{[14]}\end{array}$ & $\begin{array}{l}\text { Chronic, (>17 months); } \\
8 \text { mild to moderate } \\
\text { aphasics with anomia; } \\
\text { all left fronto-temporal } \\
\text { lesions; within patient } \\
\text { alternating treatment } \\
\text { design; no control. }\end{array}$ & $\begin{array}{l}12 \text { anomia treatment } \\
\text { sessions: } 6 \text { using PCA, } \\
\text { and } 6 \text { SFA. } 3 \text { sessions } \\
\text { per week over } 4 \\
\text { weeks. }\end{array}$ & $\begin{array}{l}\text { 7/8 patients improved } \\
\text { naming accuracy for items } \\
\text { treated with } P C A ; 63 \% .\end{array}$ & $\begin{array}{l}\text { fMRI: pre and directly post } \\
\text { treatment. } \\
\text { Task: picture naming } \\
\text { compared to a low level } \\
\text { baseline (fixation cross). }\end{array}$ & $\begin{array}{l}\text { Post treatment } 7 / 8 \text { patients } \\
\text { activated predominantly left } \\
\text { hemisphere regions to the same } \\
\text { degree for treated items and } \\
\text { correctly named pre-treated items; } \\
\text { treatment engaged pre-existing } \\
\text { successful naming mechanisms. } \\
\text { LSTG activation positively } \\
\text { correlated with PCA treatment } \\
\text { outcome. }\end{array}$ \\
\hline $\begin{array}{l}\text { Jungblut } \\
{[19]}\end{array}$ & $\begin{array}{l}\text { Chronic, }>18 \text { months; } \\
3 \text { severe non-fluent } \\
\text { aphasics with speech } \\
\text { apraxia; extensive left } \\
\text { fronto-temporal lesions: } \\
\text { no control; case series } \\
\text { approach. }\end{array}$ & $\begin{array}{l}\text { The applied rhythmic- } \\
\text { melodic voice training } \\
\text { (SIPARI); } 50 \text { hours } \\
\text { over } 25 \text { weeks; }\end{array}$ & $\begin{array}{l}\text { All patients improved on the } \\
\text { vowel chanting fMRI task } \\
\text { (level 1);12.5\% }\end{array}$ & $\begin{array}{l}\text { fMRI: pre and directly post } \\
\text { treatment. } \\
\text { Task: repetition of } \\
\text { chanted vowel changes in } \\
\text { rhythm sequences with } 3 \\
\text { complexity levels. } \\
\text { Vowel changes with : } \\
\text { 1) regular groupings, } \\
\text { 2) regular groupings and rest, } \\
\text { 3) irregular grouping. }\end{array}$ & $\begin{array}{l}\text { Post-treatment all patients } \\
\text { significantly increased } \\
\text { perilesional activation commonly } \\
\text { in the left superior temporal } \\
\text { gyrus. }\end{array}$ \\
\hline $\begin{array}{l}\text { Al-Janabi } \\
{[18]}\end{array}$ & $\begin{array}{l}\text { Chronic; non-fluent } \\
\text { aphasics; 2; left fronto- } \\
\text { temporal damage; } \\
\text { within patient sham } \\
\text { control. }\end{array}$ & $\begin{array}{l}\text { MIT and rTMS } \\
\text { delivered to right IFG: } \\
2 \text { blocks of } 340 \mathrm{~min} \\
\text { sessions of MIT with } \\
\text { TMS or sham. }\end{array}$ & Unclear. & $\begin{array}{l}\text { fMRI: } 2 \text { tasks: } \\
\text { automatic speech and } \\
\text { name /read an item. }\end{array}$ & $\begin{array}{l}\text { Post-treatment both patients had } \\
\text { bilateral IFG activation changes } \\
\text { on the automatic speech task only. } \\
\text { This was not correlated with } \\
\text { behaviour. }\end{array}$ \\
\hline
\end{tabular}




\begin{tabular}{|c|c|c|c|c|c|}
\hline $\begin{array}{l}\text { Della Rosa } \\
{[16]}\end{array}$ & $\begin{array}{l}\text { Acute (4 weeks post } \\
\text { stroke); } 2 \text { sub-cortical } \\
\text { anomic aphasics. I } \\
\text { patient crossed aphasic. }\end{array}$ & $\begin{array}{l}\text { Phase } 1 \text { (P1): } 60 \text { hours } \\
\text { phonological training } \\
\text { over 3months } \\
\text { Phase } 2(\mathrm{P} 2) \text { : general } \\
\text { speech production } \\
\text { therapy for } 6 \text { months. } \\
\text { Dose not supplied }\end{array}$ & $\begin{array}{l}\text { Post-treatment: } \\
\text { Abs naming improvement in } \\
\text { Crossed aphasic: } 8 \%, 21 \% \text {; } \\
\text { Standard aphasic: } 12.5 \% \text {, } \\
14 \% \text {. }\end{array}$ & $\begin{array}{l}\text { fMRI: pre treatment, post P1 } \\
\text { and post } \mathrm{P} 2 \text { treatment. } \\
\text { Task: picture naming }\end{array}$ & $\begin{array}{l}\text { Post treatment: both patients had } \\
\text { changes in left IFG and bilateral } \\
\text { insula. The standard aphasic also } \\
\text { had changes in right IFG } \\
\text { activation patterns post P2 } \\
\text { treatment. }\end{array}$ \\
\hline Abel [13] & $\begin{array}{l}\text { Chronic ( }>4 \text { months); } \\
\text { moderate anomia; } 14 \text {, } \\
\text { left fronto-temporal } \\
\text { lesions }\end{array}$ & $\begin{array}{l}4 \text { weeks of lexical } \\
\text { therapy. Alternating } \\
\text { weeks of phonological } \\
\text { semantic therapy. } \\
\text { Hours of treatment not } \\
\text { reported. }\end{array}$ & $\begin{array}{l}\text { Abs naming improvement: } \\
\text { Overall } 10 \% \text {, } \\
\text { Trained items: } 20 \% \text {, } \\
\text { Untrained control items: } \\
10 \% \text {. } \\
\text { Untrained mastered items: } \\
\text { decreased by } 10 \% \text {. }\end{array}$ & $\begin{array}{l}\text { fMRI: pre and post therapy } \\
\text { Task: picture naming }\end{array}$ & $\begin{array}{l}\text { LIFG opercular activation pre } \\
\text { treatment correlated with therapy } \\
\text { outcome and lesion size. }\end{array}$ \\
\hline Abel [12] & Same as above. & Same as above. & Same as above. & Same as above. & $\begin{array}{l}\text { Post treatment ICA analyses } \\
\text { found activation decreases in left } \\
\text { IFG with increases in bilateral } \\
\text { prefrontal areas. }\end{array}$ \\
\hline $\begin{array}{l}\text { Tuomiranta } \\
{[17]}\end{array}$ & $\begin{array}{l}\text { Chronic, (>33 months); } \\
1 \text { (AA); extensive left } \\
\text { temporal lesion; deep } \\
\text { dysphasia. }\end{array}$ & $\begin{array}{l}\text { Learning and long- } \\
\text { term maintenance of } \\
\text { 1.novel words. } 4 \\
\text { sessions. } \\
\text { 2. familiar words } \\
\text { through home } \\
\text { computer training. } 18 \\
\text { days }\end{array}$ & $\begin{array}{l}\text { 1. AA's novel word learning } \\
\text { on par with healthy controls } \\
100 \% \text {, immediately and } 6 \\
\text { months later. } \\
\text { 2. Trained words } 100 \% \text {, } \\
9 \text { weeks later } 80 \%\end{array}$ & $\begin{array}{l}\text { fMRI: } 2 \text { experiments. } \\
\text { 1) Reading a)familiar } \\
\text { words, } \\
\text { b)pseudowords, } \\
\text { c)false fonts. } \\
\text { 2) Word learning similar } \\
\text { to treatment } 1 .\end{array}$ & $\begin{array}{l}\text { 1. When reading AA had right } \\
\text { lateralised activation in the } \\
\text { temporo-parietal regions. } \\
\text { 2. AA was unable to learn words } \\
\text { in the scanner so the fMRI data } \\
\text { was not interpretable. }\end{array}$ \\
\hline
\end{tabular}

Legend: $\mathrm{BG}=$ basal ganglia; $\mathrm{BNT}=$ Boston naming test $; \mathrm{F}-\mathrm{T}-\mathrm{P}=$ Fronto-temporal -parietal; $\mathrm{I}=$ Insula; $\mathrm{ICA}=$ independent components analysis; ILAT = intensive language action therapy; $\mathrm{MCA}=$ middle cerebral artery; $\mathrm{MIT}=$ Melodic Intonation Therapy; $\mathrm{PCA}=$ phonological Components Analysis; $\mathrm{ROI}=$ region of interest; $r T M S=$ repetitive transcranial direct current stimulation; SFA= semantic feature analysis; SWA = slow wave activity; $T=$ token test; $W A B=$ Western aphasia battery 
